\title{
Human Milk output among mothers previously treated for severe acute malnutrition in childhood in Democratic Republic of Congo
}

Christine Chimanuka Murhima'Alika ${ }^{1,2^{*}}$, Ghislain Maheshe Balemba ${ }^{1,3}$, Pacifique Mwene-Batu Lyabayungu ${ }^{1,2,3,4}$, Guy Mulinganya Mulume'oderhwa ${ }^{3}$, Grace Munthali ${ }^{5}$, Victor Owino ${ }^{6}$, Albert Mwembwo Tambwe ${ }^{7}$, Michèle Dramaix ${ }^{4}$, Philippe Donnen ${ }^{4}$ and Ghislain Bisimwa Balaluka ${ }^{1,2}$

\begin{abstract}
Background: Malnutrition is a public health problem, as wasting affects $7.5 \%$ of children worldwide. The harmful effects of severe acute malnutrition (SAM) can last a lifetime, but how SAM in childhood affects later breastfeeding ability is not clear. In the present study, we assessed the human milk output and body composition among mothers with a history of childhood SAM.

Methods: This retrospective cohort study was carried out in Miti-Murhesa Health Zone (Democratic Republic of Congo) from January 15 to March 17, 2020. We selected lactating mothers with breastfed infants aged 2-12 months. Two categories of mothers were included: those who had been treated for SAM during their childhood (years 1988-2003; $n=39$ ) and a community control with no history of SAM $(n=40)$. The weight, height, and midupper arm circumference were measured and body mass index (BMI) calculated as weight/height ${ }^{2}$. Body composition and human milk output were assessed using standard deuterium dilution methods. Student $\mathrm{t}$ and $\mathrm{chi}^{2}$ tests ware applied to compare two groups.

Results: The mean age \pm standard deviation of the mothers was $24.4 \pm 5.1$ and $26.0 \pm 6.1$ years for the SAM and control groups, respectively $(p=0.186)$. The age of their infants was $5.4 \pm 2.3$ months in both groups $(p=0.962)$. In the SAM and control groups, the mean maternal BMI was $23.8 \pm 2.3$ and $23.6 \pm 3.7 \mathrm{~kg} / \mathrm{m}^{2}(p=0.849)$, mean Fat Mass $27.1 \% \pm 5.0$ and $27.1 \% \pm 5.8 \%(p=0.708)$, and the mean Fat Free mass $72.9 \% \pm 5.0$ and $72.9 \% \pm 5.8 \%(p=0.998)$, respectively. Human milk output was $833.7 \pm 152.1 \mathrm{~g} / \mathrm{d}$ in SAM group and $827.4 \pm 171.4 \mathrm{~g} / \mathrm{d}$ in the control group $(p=0.864)$.
\end{abstract}

Conclusions: We found no significant difference in human milk output and body composition in mothers treated for SAM during childhood compared to community controls.

Keywords: Childhood malnutrition, Lactating mother, Body composition, Human milk output, D.R.Congo

\footnotetext{
* Correspondence: christinechimanuka@gmail.com

'Ecole Régionale de Santé Publique, Université Catholique de Bukavu, Bukavu, Democratic Republic of Congo

${ }^{2}$ Centre de Recherche en Sciences Naturelles de Lwiro, Lwiro, Democratic Republic of Congo

Full list of author information is available at the end of the article
}

(c) The Author(s). 2021 Open Access This article is licensed under a Creative Commons Attribution 4.0 International License, which permits use, sharing, adaptation, distribution and reproduction in any medium or format, as long as you give appropriate credit to the original author(s) and the source, provide a link to the Creative Commons licence, and indicate if changes were made. The images or other third party material in this article are included in the article's Creative Commons licence, unless indicated otherwise in a credit line to the material. If material is not included in the article's Creative Commons licence and your intended use is not permitted by statutory regulation or exceeds the permitted use, you will need to obtain permission directly from the copyright holder. To view a copy of this licence, visit http://creativecommons.org/licenses/by/4.0/ The Creative Commons Public Domain Dedication waiver (http://creativecommons.org/publicdomain/zero/1.0/) applies to the data made available in this article, unless otherwise stated in a credit line to the data. 


\section{Introduction}

Malnutrition is a public health problem, especially in low and medium-income countries (LMICs). According to the latest Global Nutrition Report, the prevalence of stunting for children age 6-59 months was $22.2 \%$, or 150.8 million children, in 2018, and approximately $7.5 \%$, or 50.3 million children, suffered from wasting [1, 2]. An estimated 5.8 million deaths occur each year among children under 5 years old [3], $45 \%$ of which are attributed to malnutrition [4].

Various studies have shown that malnutrition in childhood has adverse health consequences, including heightened risk of metabolic diseases, such as hypertension, diabetes, and obesity, in adolescence and adulthood [5-8].

Studies conducted on a cohort of former subjects treated for SAM during childhood in the DRC showed that surviving males exposed to childhood SAM had low body weight, short height, but no difference for females [9] . Also subjects exposed to SAM during childhood had an overall higher risk of developing metabolic syndrome, carbohydrate metabolism disorder and a higher prevalence of diabetes and hypertension [10, 11]. SAM survivors also had a low socioeconomic level and reduced cognitive abilities compared to subjects not exposed to SAM [12] .

In addition, the prevalence of malnutrition in the adult population in increasing globally, particularly wasting and obesity $[13,14]$.

The WHO recommends exclusive breastfeeding in the first 6 months of life, followed by the introduction of nutritious complementary foods and continued breastfeeding for at least 2 years of life to prevent malnutrition among infants and young children [15]. Good breastfeeding practice requires the lactating mother to have an adequate nutritional status, and some studies have established associations between the nutritional parameters of the mother and the weight of the newborn [16-18].

Most authors agree that lactating mothers, excluding those with severe pathologies, have sufficient human milk output to ensure breastfeeding, though there is some variation with, for example, maternal age, parity, the age of the breastfed infant, and the season $[19,20]$.

The most common methods of assessing human milk are the daily weighing of the mother-infant pair [21] and the administration of deuterium oxide to the mother [22] and these two methods have just been analyzed recently by Jacqueline K., each of them having its advantages and its limits [23]. Also, a recent study shows the need to understand the milk as a biological system given its complexity and its multiple variations between groups of lactating mothers and for the same lactating mother in the time [24].

Previous studies in Eastern Democratic Republic of Congo (DRC) have shown that, even for lactating mothers with borderline nutritional status, the composition of human milk is adequate, though the daily human milk output may be low in cases of severe undernutrition [25]. At the time, Hennart's work did not establish a significant difference in the macronutrient content of human milk of malnourished mothers other than a low fat content. However, a recent systematic review shows a positive association between the mother's body mass index (BMI) and the fat content of human milk, without any difference in the protein and carbohydrate content [26]. So an expert workshop concluded that more studies are needed to better understand the different variations in the quantity and composition of human milk [27].

How exposure to malnutrition in childhood may influence a mother's the ability to produce adequate breast milk is not clear. Researchers are currently working to highlight the long-term effects of severe acute malnutrition (SAM) in childhood. Body composition analysis and anthropometric measurements provide a better understanding of the double burden of malnutrition [28].

Though the harmful effects of SAM can last a lifetime, how SAM in childhood can affect the ability of mothers to breastfeed their offspring is not yet known.

To the best of our knowledge, no studies have been published on lactation performance and lactating mothers exposed to SAM in childhood who survived in a context of endemic malnutrition without going through the nutritional transition described in industrialized countries [29, 30]. The objective of our study is to assess whether previous exposure to childhood SAM impact human milk production of lactating mothers who have lived in a context of endemic malnutrition. Thus, we sought to compare the Human milk output of lactating mothers exposed to SAM during their childhood to that of lactating mothers who did not suffer from SAM. This should contribute to a better understanding of the long-term effects of SAM in childhood and establish evidence to strengthen breastfeeding practices in a context of endemic malnutrition.

\section{Materials and methods \\ Study setting}

The study was carried out in the health zone (HZ) of Miti-Murhesa located $33 \mathrm{~km}$ from Bukavu city in the province of South Kivu in Eastern DRC. The HZ central office is located $9 \mathrm{~km}$ from the Natural Sciences Research Centre of Lwiro (CRSN) within which the Lwiro Pediatric Hospital (LPH) operates. This HZ is between 1500 and $2000 \mathrm{~m}$ above sea level [31]. Rural people live on subsistence farming with traditional food practices in a context of poverty and overcrowding. Breastfeeding is provided for all infants, but weaning occurs early from the first months and is based on unsuitable local foods. The most recent nutritional surveys carried out in the 
territory of Kabare, which includes four HZs, including Miti-Murhesa, confirm this endemic malnutrition with a constant prevalence of overall acute malnutrition of $11.9 \%$ in children aged 6-59 months and a prevalence of chronic malnutrition of $58.4 \%$ [32]. National surveys conducted over the past two decades confirm the high prevalence of malnutrition in the province of South Kivu [33].

\section{Study design and subjects}

This was a retrospective cohort study in which we identified lactating mothers who had been exposed to SAM in their childhood and whose infants were aged 2-12 months at the time of enrollment. The mothers had been treated and cured of SAM at LPH during their childhood, between 1988 and 2003. The LPH specialized in the management of malnourished children in the Eastern of The Democratic Republic of Congo. Research is currently underway to study the long-term effects of SAM in adult subjects who were treated for SAM in their childhood between 1988 and 2007. Their clinical and anthropometric parameters were traced through the LPH registers and the electronic database of the LPH [9]. At that time, a diagnosis of SAM at LPH was based on the weight to height ratio plotted on the local child growth curve established by De Meyer in 1959, the presence of nutritional edema, and serum albumin levels $[9,34,35]$.

The nutritional status of the women at the time of their admission to the hospital as children was reassessed in relation to the WHO child growth standard of 2006 [36]. A new classification was established according to the following criteria. A child was classed as having SAM if they met at least one of the following criteria: mid-upper arm circumference $($ MUAC) $<115 \mathrm{~mm}$, weight to height $<-3 \mathrm{Z}$-score $(\mathrm{Z}-\mathrm{Sc})$, and the presence of nutritional edema in the hands and/or feet and/or face. Oedematous malnutrition was defined by the presence of nutritional edema in the hands and/or feet and/ or face. Severe wasting was based on a MUAC $<115 \mathrm{~mm}$ and/or a weight to height $<-3 \mathrm{Z}$-Sc without edema. The mixed form was defined by the presence of nutritional edema with either a MUAC $<115 \mathrm{~mm}$ or a weight to height $<-3$ Z-Sc or both [36]. The latter classification of nutritional status was used for the analyses in this study.

The community controls were not exposed to SAM in their childhood and enrolled from the same villages. Data collection for this study was carried out from January 15 to March 17, 2020.

\section{Identification of population}

Eligible participants were identified by a team of 4 doctors, including the study coordinator, 2 nutritionists, 2 assistant nutritionists, and 16 community health workers (CHWs). Mothers exposed to SAM during childhood were identified from the electronic database and the
1988-2003 LPH registers [35]. By consulting the electronic database and the LPH registers, we categorized lactating mothers if they were previously edematous as SAM-kwashiorkor or SAM-marasmus. The assistant nutritionists and CHWs collaborated with all of the village chiefs of Miti-Murhesa HZ to locate the actual residences of targeted lactating mothers. The community controls were lactating mothers who had children of the same age and were recruited from the same villages as the mothers exposed to SAM considering the closest case according to the door-to-door distance. In recruiting controls lactating mothers, we cross-referenced the records of nutritional centers at the time to exclude all cases that had been admitted to a nutritional center (therapeutic or supplementation). Then the witnesses were confirmed by the $\mathrm{CHW}$ and village chiefs as having grown up in well-known families with no history of acute malnutrition. These are lactating mothers who grew up in families known to have a higher socioeconomic level and who did not experience food problems in childhood. Both assistant nutritionists and some CHWs have collaborated with the CRSN in a community nutrition program since 1990 and know the majority of children in Miti-Murhesa who have suffered from malnutrition in each village. Lactating mothers identified in different health areas and villages were referred to the four targeted health centers (Buhandahanda, Chegera, Kavumu, Mulungu) for study-related assessments. All mothers and infants were in apparent good health at the time of the study (No clinical signs such as fever, diarrhea, major pain or hospitalization in the previous three months).

\section{Outcomes}

The main expected result is to compare human milk output in the two groups of lactating mothers (exposed to SAM in childhood and unexposed). For this purpose, our study aims to evaluate the quantity of human milk output by the lactating mothers by the deuterium dilution method. And as a secondary objective our study aims to compare the body composition of lactating mothers according to the two-compartment model: Fat Mass (FM) and Fat Free Mass (FFM).

\section{Sample size}

Sample size was determined based on the number of lactating mothers who had been treated for childhood SAM and had infants aged 2-12 months that were identified in the targeted health areas during the study period. Thus we have included a total of 79 mothers, 39 exposed and 40 unexposed. Referring to previous studies whose the minimum size of 27 lactating mothers per group was required based on a mean difference between the two groups of 100 and standard deviation of $130 \mathrm{~g} / \mathrm{d}$ 
for $80 \%$ power [37-39].; the size of 36 lactating mother per group was associated with a power of $90 \%$ if we consider the alpha error of $0.05 \%$ [40].

\section{Anthropometric measurements}

For the breast-fed infants, body weight was measured to the nearest $100 \mathrm{~g}$ using a Salter scale but no other nutritional assessments were carried out. For lactating mothers, body weight was measured to the nearest $100 \mathrm{~g}$ using an electronic scale (OMRON, HN-289-EBK) while the subject was dressed only in light clothing. Height was determined to the nearest $0.1 \mathrm{~cm}$ without shoes using a SECA $206 \mathrm{~cm}^{\circ}$ measuring tape attached to a wall. The MUAC was measured using an adult MUAC tape. The anthropometric measurements were carried out in accordance with WHO guidelines [36, 41] and subjected to quality control based on independent measurements by two members of the team. The final measurement was the average of the two. In the case of a deviation of more than $300 \mathrm{~g}$ for the weight and $0.5 \mathrm{~cm}$ for the height, a third measurement was taken. The average of the two closest measurements was used. Body mass index (BMI) was calculated as weight/height ${ }^{2}$.

\section{Human milk output and mother's body composition}

The mothers' body composition and human milk output were determined by the Deuterium oxide Dose-toMother Technique (DDMT) using $\mathrm{D}_{2} \mathrm{O}$ in the protocol validated by the IAEA [22, 42]. Doses of $\mathrm{D}_{2} \mathrm{O}(99.8$ atom $\% \mathrm{D}$, Cambridge Isotope Laboratories Inc., Andover, USA) of $30 \mathrm{~g}$ were accurately weighed to the nearest $0.001 \mathrm{~g}$ in sterile leak-proof autoclavable polypropylene dose bottles on a calibrated analytical balance (Sartorius $0.0001 \mathrm{~g}$; Sartorius AG, Goettingen, Germany) at the Laboratory of the Hôpital Provincial Géneral de Référence Bukavu (University Clinic of Catholic University of $\mathrm{Bu}-$ kavu). After consenting, baseline saliva samples were collected from the mother and baby. The mother was asked to rotate a small ball of cotton wool around their mouth until it was completely soaked with saliva. The cotton ball was placed in a $10-\mathrm{mL}$ sterile disposable syringe and the plunger depressed to transfer the saliva into a 3.6-mL sterile cryovial labeled with the mother's code, the date, and the time of sample collection. Saliva samples were then collected from the babies by a trained technician using a cotton wool swab wrapped with extra cotton wool. The saliva was collected by moving the swab around the baby's mouth until it was completely soaked with saliva.

Post-dose saliva samples were collected from the mothers and infants on days $1,2,3,4,13$, and 14 after the $30 \mathrm{~g}$ deuterium dose was consumed. Deuterium abundance in the saliva was measured using a Fourier transform infrared spectrometer (Agilent Technologies,
Malaysia, model $4500 \mathrm{~s}$ ), and the enrichment was calculated by subtracting the value of the baseline sample from the value of the post-dose sample [43].

Human milk output was determined based on a twocompartment model described by Coward et al. [44] by fitting the isotopic enrichment data to a model for water turnover in the mothers and infants. Maternal body composition was determined from the mother's total body water (TBW), which was calculated from they-intercept of the mother's isotope elimination curve and the weight of $\mathrm{D}_{2} \mathrm{O}$ consumed corrected for non-aqueous isotope exchange. The FFM was determined by dividing TBW by 0.732, the assumed hydration of the FFM [45]. The FM was the difference between body weight and the FFM. Curve fitting and calculation of the output were performed using a spreadsheet template provided by the IAEA.

All methods were carried out in accordance with relevant guidelines and regulations.

\section{Data analysis}

The data were encoded in Microsoft Excel. We used SPSS 23.0 software to analyze the data. For the quantitative variables, we checked the normality with the Normal Plot and the Levene test was applied to check the homoscedacity. The quantitative data were presented as means and standard deviation (SD) and categorical data as numbers and percentages. The student $t$ test was used to compare the body composition, weight, height, and human milk output means. Pearson's $\mathrm{Chi}^{2}$ test was used to compare the proportions (or Fisher's exact test if the $\mathrm{Chi}^{2}$ was not valid). One-way ANOVA was used to compare means in different categories of childhood SAM among mothers in the exposure group. We considered the significance level of 0.05 .

\section{Results}

A total of 79 lactating mothers with infants aged 2 to 12 months were included in the study (39 lactating mothers exposed to SAM during childhood and 40 community controls). The characteristics of the mothers and infants are given in Table 1 . We found no difference in the weight of breastfed infants or in the weight, height, and MUAC of mothers in the SAM and control groups.

The mother's body composition and lactation performance are described in Table 2. We found no significant differences between the two groups of lactating mothers in regards to the BMI, FM, TBW, and breast milk output.

The body composition and lactation performance of the SAM group based on type of malnutrition during childhood are described in Table 3. Applying the WHO classification criteria (weight to height ratio, edema, and MUAC), we found no significant difference between the 
Table 1 Characteristics of the mothers and infants

\begin{tabular}{|c|c|c|c|}
\hline Characteristic & Exposed $(n=39)$ & Community Control $(n=40)$ & $P$-value \\
\hline \multicolumn{4}{|l|}{ Infants } \\
\hline Age, months & $5.4 \pm 2.3$ & $5.4 \pm 2.3$ & 0.96 \\
\hline Female & $43.6 \%$ & $45.0 \%$ & 0.90 \\
\hline Weight, kg & $6.7 \pm 1.3$ & $6.6 \pm 1.4$ & 0.56 \\
\hline WHZ (mean,SD) & $1.04 \pm 1.53$ & $0.48 \pm 1.80$ & 0.75 \\
\hline$\% \mathrm{WHZ}<-2,0$ & $0.0 \%$ & $5.0 \%$ & $0.49^{*}$ \\
\hline WAZ (mean,SD) & $-0.67 \pm 1.2$ & $0.88 \pm 1.2$ & 0.43 \\
\hline$\% W A Z<-2,0$ & $12.8 \%$ & $15.0 \%$ & 0.52 \\
\hline HAZ (mean,SD) & $-1.89 \pm 1.6$ & $-1.47 \pm 2.7$ & 0.42 \\
\hline$\% H A Z<-2,0$ & $46.2 \%$ & $37.5 \%$ & 0.44 \\
\hline \multicolumn{4}{|l|}{ Mothers } \\
\hline Age, years & $24.4 \pm 5.1$ & $26.0 \pm 6.1$ & 0.19 \\
\hline Weight, kg & $55.2 \pm 7.5$ & $55.9 \pm 7.0$ & 0.69 \\
\hline Height, cm & $152.2 \pm 6.3$ & $153.7 \pm 5.1$ & 0.24 \\
\hline MUAC, mm & $253.8 \pm 26.4$ & $258.9 \pm 20.0$ & 0.34 \\
\hline MUAC $<230 \mathrm{~mm}$ & $7.7 \%$ & $10.0 \%$ & $1.00^{*}$ \\
\hline Height $<150 \mathrm{~cm}$ & $35.9 \%$ & $22.5 \%$ & 0.19 \\
\hline Height $<145 \mathrm{~cm}$ & $10.3 \%$ & $2.5 \%$ & $0.20^{*}$ \\
\hline Weight < $50 \mathrm{~kg}$ & $28.2 \%$ & $10.0 \%$ & $0.05^{*}$ \\
\hline Weight < 45 kg & $2.6 \%$ & $7.5 \%$ & $0.61^{*}$ \\
\hline \multicolumn{4}{|c|}{ Mother's childhood status $(n=39)$} \\
\hline SAM - with edema (\%) & $64.1 \%$ & - & - \\
\hline SAM - no edema (\%) & $35.9 \%$ & - & - \\
\hline
\end{tabular}

Data are given as mean $\pm S D$ or the proportion of participants (\%) unless otherwise noted. SAM = severe acute malnutrition; MUAC = mid-upper arm circumference

* Fischer exact test

human milk output of lactating mothers treated for SAM (edema, severe wasting or mixed-type).

\section{Discussion}

The purpose of this study was to compare human milk output and body composition in a group of lactating mothers with a history of SAM in childhood to these values in a community control group. Overall, we did not observe a significant difference between the two groups. To the best of our knowledge, no studies have specifically measured the human milk output and body composition of lactating mothers with a history of SAM in sub-Saharan Africa.

Our findings on human milk output are similar to those described in other studies conducted in the region, which range between 650 and $850 \mathrm{~g} / \mathrm{d}[16,22]$ with small differences attributable to a difference in the methods used or the age of the breastfed infants [19]. By using

Table 2 Human milk output and Body composition

\begin{tabular}{llll}
\hline Variable & Exposed to SAM $(\boldsymbol{n}=\mathbf{3 9 )}$ & Community Control $(\boldsymbol{n}=\mathbf{4 0})$ & $\boldsymbol{P}$-value \\
\hline BMl, kg/m² & $23.8 \pm 2.3$ & $23.6 \pm 3.7$ & 0.85 \\
Body fat, kg & $15.1 \pm 4.0$ & $15.0 \pm 5.0$ & 0.92 \\
Fat mass, \% & $27.1 \pm 5.0$ & $27.1 \pm 5.8$ & 0.99 \\
Fat-free mass, kg & $40.1 \pm 5.1$ & $40.5 \pm 4.1$ & 0.69 \\
Fat-Free mass, \% & $72.9 \pm 5.0$ & $72.9 \pm 5.8$ & 0.99 \\
Total body water, kg & $29.3 \pm 3.7$ & $29.7 \pm 3.0$ & 0.65 \\
Total body water, \% & $53.4 \pm 3.7$ & $53.4 \pm 4.3$ & 0.99 \\
Breast milk output, g/d & $833.7 \pm 152.2$ & $827.4 \pm 171.4$ & 0.86 \\
\hline
\end{tabular}

Data are presented as mean $\pm S D$. SAM = severe acute malnutrition; $M U A C=$ mid-upper arm circumference 
Table 3 Characteristics, body composition, and Human milk output by type of malnutrition in childhood (WHO classification)

\begin{tabular}{|c|c|c|c|c|}
\hline Variable & $\begin{array}{l}\text { SAM } \\
\text { edema }(n=15)\end{array}$ & $\begin{array}{l}\text { SAM mixed-type } \\
(n=10)\end{array}$ & $\begin{array}{l}\text { SAM } \\
\text { severe wasting }(n=11)\end{array}$ & $P$-value* \\
\hline \multicolumn{5}{|l|}{ Infants } \\
\hline Age, months & $5.3 \pm 2.4$ & $4.8 \pm 2.1$ & $6.7 \pm 1.3$ & 0.66 \\
\hline Weight, kg & $6.9 \pm 1.5$ & $6.5 \pm 1.0$ & $6.6 \pm 1.2$ & 0.71 \\
\hline \multicolumn{5}{|l|}{ Mothers } \\
\hline Age, years & $24.5 \pm 5.5$ & $26.4 \pm 5.7$ & $22.6 \pm 3.3$ & 0.27 \\
\hline Weight, kg & $58.1 \pm 6.7$ & $54.3 \pm 9.4$ & $52.0 \pm 5.4$ & 0.11 \\
\hline Height, cm & $152.8 \pm 5.5$ & $152.7 \pm 7.6$ & $150.6 \pm 6.7$ & 0.66 \\
\hline MUAC, mm & $265.1 \pm 19.7$ & $247.9 \pm 19.4$ & $252.2 \pm 15.7$ & 0.06 \\
\hline \multicolumn{5}{|l|}{ Body composition } \\
\hline $\mathrm{BMI}, \mathrm{kg} / \mathrm{m}^{2}$ & $24.8 \pm 1.8$ & $23.2 \pm 3.0$ & $22.9 \pm 1.7$ & 0.07 \\
\hline Body fat, kg & $16.7 \pm 3.9$ & $13.9 \pm 4.8$ & $14.1 \pm 3.2$ & 0.15 \\
\hline Body fat, $\%$ & $28.7 \pm 5.2$ & $25.1 \pm 5.6$ & $26.9 \pm 4.4$ & 0.23 \\
\hline Fat-Free mass, kg & $41.4 \pm 5.2$ & $40.4 \pm 5.8$ & $37.9 \pm 3.6$ & 0.22 \\
\hline Fat-Free mass, \% & $71.3 \pm 5.2$ & $74.9 \pm 5.6$ & $73.1 \pm 4.4$ & 0.23 \\
\hline Total body water, kg & $30.3 \pm 3.8$ & $29.6 \pm 4.2$ & $27.8 \pm 2.7$ & 0.22 \\
\hline Total body water, $\%$ & $52.2 \pm 3.8$ & $54.7 \pm 4.1$ & $53.5 \pm 3.2$ & 0.24 \\
\hline \multicolumn{5}{|l|}{ Human milk output } \\
\hline Breast milk output, g/d & $881.3 \pm 147.7$ & $872.5 \pm 156.3$ & $776.7 \pm 135.4$ & 0.18 \\
\hline
\end{tabular}

Data are presented as mean $\pm S D$

* ANOVA applied to compare the three SAM groups

the DDMT, Owino et al. measured breast milk output of $678 \pm 285.4 \mathrm{~g} / \mathrm{d}$ for lactating mothers with infants $9-10$ months old recruited in the same $\mathrm{HZ}$ without considering the mother's nutritional status in childhood [37]. These values are higher than those reported by Donnen in 1997 $(605 \mathrm{~g} /$ day) in mothers whose infants were 2-4 months old [46], but it is difficult to compare these results because the DDMT has more precision than the methods used at the time (weighing of mother and infant).

The observed values are also similar to those reported in other countries by researchers using DDMT. Matsiko et al. recently worked on a mixed sample of breastfeeding mothers recruited in a rural health district in Rwanda and Holland and reported $854.5 \pm 222.3 \mathrm{~g} / \mathrm{d}$ with breastfed infants aged 3-7 months. These mothers had body composition values similar to those observed in our study, but they had a higher average height and weight $(162.6 \mathrm{~cm}$ and $61.5 \mathrm{~kg})$ [47]. Researchers in other countries, including Malawi [48], South Africa [49], and 12 countries across continents [50], have reported similar values, but with small variations related to the age of the breastfed infant. The human milk output values are also similar to those obtained in other countries, including Indonesia, where breastfeeding practices were assessed using the same method $(787 \pm 149 \mathrm{~g} / \mathrm{d})$ but with mothers whose average BMI and FM are $24.0 \mathrm{~kg} / \mathrm{m}^{2}$ and $33.4 \%$, respectively [51].
The body composition variables were also similar in the two groups of lactating mothers in this study, probably due to the physiological adaptation mechanism of the mother during pregnancy also applying to mothers with a history of SAM in childhood. Widen and Gallagher [16] reported that pregnant women had gained weight, FM, and TBW during pregnancy, with a subsequent decline postpartum, and this weight gain can persist until 27 weeks postpartum $[16,52]$, corresponding to the average age of the children of lactating mothers in our study. The authors identified a few predictors of this gestational weight gain: initial BMI, parity, and age. Thus, lean women have greater weight gain than women with a high initial BMI, and primiparous women have greater weight gain than multiparous women [15, 52-55].

In the present study, the lactating mothers with a history of SAM had a similar BMI as the control group. This BMI is similar to European lactating mothers of various nationalities $\left(22.7 \pm 2.6 \mathrm{~kg} / \mathrm{m}^{2}\right)$, but they had more robust anthropometric parameters with a mean weight of $61.7 \pm 7.7 \mathrm{~kg}$ and height of $164.9 \pm 9.0 \mathrm{~cm}$ [56] Our results are also similar to those observed in lactating mothers in rural Pakistan (BMI $22.9 \pm 6.1 \mathrm{~kg} / \mathrm{m}^{2}$; human milk output $757 \pm 249 \mathrm{~g} / \mathrm{d}$ ) but with a higher percentage of FM $(31 \pm 13 \%)$ (46). In general, the observed BMI and FM are similar to the values observed in most LMICs, such as Malawi, Bangladesh, Brazil, and 
Mexico. Only Kenya has a lower reported BMI and percent body fat in one of two studies (BMI $18.6 \pm 1.0 \mathrm{~kg} /$ $\mathrm{m}^{2}$; FM $17 \pm 6 \%$ ); the second study reported a higher FM percentage (22 $\pm 6 \%)$ [57].

Mothers with a history of oedema had higher human milk output than those with severe wasting but with no statistically significant difference, probably due to the small sample size (Table 3). It is possible that mothers with a history of severe wasting are more affected by relative malnutrition because they have a large proportion of subjects with height $<150 \mathrm{~cm}(50.0 \%$ vs. $28.0 \%)$ and weight $<50 \mathrm{~kg}(42.8 \%$ vs. $20.0 \%)$ compared to the other group. A larger sample size may allow us to understand the differences between exposure to edema and exposure to severe wasting knowing that, during childhood, children may develop both forms at different times!

A few studies have reported a large variation in breast milk output in the context of malnutrition. Hennart showed that malnourished lactating mothers may have a human milk output $<400 \mathrm{~g} / \mathrm{d}$ [25]. Another study in Kenya showed that high food insecurity is associated with a reduction in daily human milk intake [51]. However, the last two studies refer to mothers examined in the context of present malnutrition without referring to malnutrition in childhood! These results from the Lwiro cohort suggest that the amount of human milk produced is likely to be related to the environmental and nutritional context in which lactating mothers live rather than to their nutritional status during their childhood. This theory has already been evoked by other authors to emphasize that the long-term effects of malnutrition are strongly linked to the context in which malnourished survivors evolve [58].

Despite these results, which provide a general overview of the long-term effects of SAM in childhood on the lactating performance of mothers, our study has two major limitations. First, we did not have data on the nutritional status (anthropometric and clinical parameters) of the community control group during their childhood. Therefore, there is no irrefutable evidence that the community control group did not contain mothers who experienced moderate malnutrition during childhood. At that time, the MUAC was not used to screen cases of malnutrition in the region. The protocol was based on the weight to height ratio plotted on the local child growth curve and clinical signs of edema or severe wasting $[34,35]$. However, we can ascertain that the lactating mothers in the control group had never been admitted to the nutritional center outside the LPH and that they never had kwashiorkor or severe marasmus. At the time, there was a community-based program to detect SAM in the villages of the Miti-Murhesa HZ. Also, the control group included mothers from families well known to the community relays and village chiefs, and these various cross testimonies confirmed that these were good families with no history of malnutrition. What is reassuring for our study is that these community control groups represent the local population, and that these subjects do not have experience with nutritional transition because they lived in an environment where malnutrition has remained endemic. The second limitation is the size of the sample even if we had included the maximum number of mothers that it was possible to have during the season. Indeed, we observed a standard deviation of 150 and $170 \mathrm{~g} /$ day whereas the initial sample size calculation was based on a standard deviation of $130 \mathrm{~g} /$ day in both groups. This reduced the expected power of our study. Also this sample size was small and did not allow us to make comparisons between subgroups (edema and wasting), but it paves the way for further studies in this area.

\section{Conclusion}

The results of our study show that, in general, SAM in childhood does not affect the lactating mother's ability to produce human milk. We found no difference in the human milk output and body composition of lactating mothers treated for SAM during childhood compared to community controls. These results suggest that all mothers need support to breastfeed optimally.

\section{Abbreviations}

IAEA: International Atomic Energy Agency; BMI: Body mass index;

CHW: Community health worker; CEMUBAC: Centre Médical de l'Université Libre de Bruxelles pour ses activités de coopération; CRSN: Centre de Recherche en Sciences Naturelles de Lwiro; DDMT: Deuterium dose mother technique; DRC: Democratic Republic of Congo; FFM: Fat-free mass; FM: Fat mass; FTIR: Fourier transform infrared spectroscopy; GWG: Gestational weight gain; HZ: Health zone; LMIC: Low and medium-income countries; LPH: Lwiro Pediatric Hospital; MUAC: Mid-upper arm circumference; RUCF: Raedy-use complementary food; RIPSEC: Renforcement institutionnel pour les politiques de santé basées sur l'Evidence en République Démocratique du Congo; SAM: Severe acute malnutrition; TBW: Total body water; WHO: World Health Organization

\section{Acknowledgements}

We are thankful to Philippe Hennart, Professor Emeritus of Université Libre de Bruxèlles and the CEMUBAC team (currently called ULB -Cooperation), who initiated the system for collecting and computerizing data on malnutrition since 1988. Our thanks also go to the entire team of doctors, nurses, and other technicians who participated in the treatment of malnourished children in Lwiro Hospital between 1988 and 2007. We also thank the Van Burren Foundation, which used to contribute to the operational costs of Lwiro Hospital. We would like to thank the IAEA for providing the equipment necessary for carrying out the body composition and breast milk intake analysis through the Regional Technical Cooperation Project (RAF6052). We also thank the RIPSEC Program for supporting the field survey costs for this study.

\section{Authors'contributions}

CCM, GMB, PML and GBB produced the original concept of the article, executed the field study (subject recruitment and data collection), and had primary responsibility for the first draft of the manuscript. GM and VO validated curves generated by the DDMT and contributed to the enrichment of the manuscript. MD and PD validated statistical data analysis, contributed to the intellectual content of the discussion. GMM and AMT contributed to the intellectual content of the discussion. The author(s) read and approved the final manuscript. 


\section{Funding}

Not applicable.

\section{Availability of data and materials}

All data generated or analyzed during this study are included in this published article [and its supplementary information files].

\section{Declarations}

\section{Ethics approval and consent to participate}

The study was authorized by the ethics committee of the Catholic University of Bukavu (UCB/CIES/NC/02B/2019) and by the technical division of the Ministry of Public Health of the DRC (South Kivu Province). All mothers enrolled in the study gave their informed consent. We attest that there is no conflict of interest in relation to this study.

\section{Consent for publication}

Not applicable.

\section{Competing interests}

The authors declare that they have no competing interests.

\section{Author details}

'Ecole Régionale de Santé Publique, Université Catholique de Bukavu, Bukavu, Democratic Republic of Congo. ${ }^{2}$ Centre de Recherche en Sciences Naturelles de Lwiro, Lwiro, Democratic Republic of Congo. ${ }^{3}$ Faculty of Medicine, Hôpital Provincial Général de Référence de Bukavu, Université Catholique de Bukavu, Bukavu, Democratic Republic of Congo. ${ }^{4}$ Ecole de Santé Publique, Université Libre de Bruxelles, Brussels, Belgium. ${ }^{5}$ National Institute for Scientific and Industrial Research of Zambia (NISIR), Lusaka, Zambia. ${ }^{6}$ Nutritional and Health Related Studies Section, Division of Human

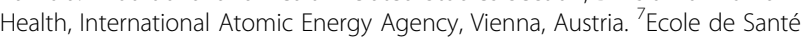
Publique de I'Université de Lubumbashi, Lubumbashi, Democratic Republic of Congo.

Received: 30 January 2021 Accepted: 15 July 2021

Published online: 25 October 2021

\section{References}

1. Development initiatives. 2018 Global Nutrition Report: Shining a light to spur action on nutrition: Bristol, UK; 2018.

2. FAO, FIDA, OMS, PAM, and UNICEF, "L'État de la sécurité alimentaire et de la nutrition dans le monde 2018. Renforcer la résilience face aux changements climatiques pour la sécurité alimentaire et la nutrition.," Rome, 2018.

3. G. 2015 C. M. Collaborators. Global, regional, national, and selected subnational levels of stillbirths, neonatal, infant, and under-5 mortality, 1980-2015 : a systematic analysis for the Global Burden of Disease Study 2015. Lancet. 2017;388(10053):1725-74. https://doi.org/10.1016/S0140-6736(1 6)31575-6.Global.

4. Black RE, Victora CG, Walker SP, Bhutta ZA, Christian P, de Onis M, et al. Maternal and child undernutrition and overweight in low-income and middle-income countries. Lancet. 2013;382(9890):427-51. https://doi.org/1 0.1016/S0140-6736(13)60937-X.

5. Ford ND, Behrman JR, Hoddinott JF, Maluccio JA, Martorell R, Ramirez-Zea $M$, et al. Exposure to improved nutrition from conception to age 2 years and adult cardiometabolic disease risk: a modelling study. Lancet Glob Heal. 2018;6(8):e875-84. https://doi.org/10.1016/\$2214-109X(18)30231-6.

6. Lee SJ, Ryu HK. Relationship between dietary intakes and the double burden of malnutrition in adults of Malang, Indonesia: an exploratory study. Nutr Res Pract. 2018;12(5):426-35. https://doi.org/10.4162/nrp.2018.12.5.426.

7. Caleyachetty R, Thomas GN, Kengne AP, Echouffo-Tcheugui JB, Schilsky S, Khodabocus J, et al. The double burden of malnutrition among adolescents: analysis of data from the global school-based student health and health behavior in school-aged children surveys in 57 low- and middleincome countries. Am J Clin Nutr. 2018;107(2):1-11. https://doi.org/10.1 093/ajcn/ngy 105.

8. Lelijveld N, Seal A, Wells JC, Kirkby J, Opondo C, Chimwezi E, et al. Chronic disease outcomes after severe acute malnutrition in Malawian children ( ChroSAM ): a cohort study. 2016:4(9):654-62. https://doi.org/10.1016/ S2214-109X(16)30133-4.
9. Mwene-Batu P, Bisimwa G, Ngaboyeka G, Dramaix M, Macq J, Lemogoum D, et al. Follow-up of a historic cohort of children treated for severe acute malnutrition between 1988 and 2007 in eastern Democratic Republic of Congo. PLoS One. 2020;15(3):1-17. https://doi.org/10.1371/journal.pone.0229675.

10. Mwene-Batu P, Bisimwa G, Ngaboyeka G, Dramaix M, Macq J, Hermans MP, et al. Severe acute malnutrition in childhood, chronic diseases, and human capital in adulthood in the Democratic Republic of Congo: the Lwiro cohort study. Am J Clin Nutr. 2021;114(1):1-10. https://doi.org/10.1093/ajcn/nqab034.

11. Mwene-Batu P, Lemogoum D, de le Hoye L, Bisimwa G, Hermans MP, Minani J, et al. Association between severe acute malnutrition during childhood and blood pressure during adulthood in the eastern Democratic Republic of the Congo: the Lwiro cohort study. BMC Public Health. 2021; 21(1):1-10. https://doi.org/10.1186/s12889-021-10908-4.

12. Mwene-Batu P, Bisimwa G, Baguma M, Chabwine J, Bapolisi A, Chimanuka $C$, et al. Long-term effects of severe acute malnutrition during childhood on adult cognitive, academic and behavioural development in African fragile countries: The Lwiro cohort study in Democratic Republic of the Congo. PLoS One. 2020;15(12):1-15. https://doi.org/10.1371/journal.pone.0244486.

13. WHO. The double burden of malnutrition. Policy brief: Geneva; 2017. https://doi.org/10.1111/j.1745-6584.1983.tb00740.x.

14. Di Cesare $\mathrm{M}$, et al. Trends in adult body-mass index in 200 countries from 1975 to 2014: a pooled analysis of 1698 population-based measurement studies with 19.2 million participants. Lancet. 2016;387(10026):1377-96. https://doi.org/10.1016/S0140-6736(16)30054-X.

15. Worl Health Organization. Global strategy for infant and young child feeding. Fifthy-fourth World Heal. Assem. No. 1; 2001. p. 5.

16. Widen EM, Gallagher D. Body composition changes in pregnancy: measurement, predictors and outcomes. Eur J Clin Nutr. 2014;68(6):643-52. https://doi.org/10.1038/ejcn.2014.40.

17. Mohanty C, Prasad R, Srikanth Reddy A, Ghosh JK, Singh TB, Das BK. Maternal anthropometry as predictors of low birth weight. J Trop Pediatr. 2006;52(1):24-9. https://doi.org/10.1093/tropej/fmi059.

18. Assefa N, Berhane $\mathrm{Y}$, Worku A. Wealth status, mid upper arm circumference (MUAC) and Ante Natal Care (ANC) are determinants for low birth weight in Kersa, Ethiopia. PLoS One. 2012;7(6):1-6. https://doi.org/10.1371/journal. pone.0039957.

19. Slater C, Kaestel P, Houghton L. Assessing breastfeeding practices objectively using stable isotope techniques. Ann Nutr Metab. 2019;75(2): 109-13. https://doi.org/10.1159/000503667.

20. Ramlal RT, et al. Patterns of body composition among HIV-infected, pregnant malawians and the effects of famine season. Matern Child Health J. 2013;17(2):265-73. https://doi.org/10.1007/s10995-012-0970-6.

21. Arthur MSPG, Hartmann PE. Measurement of the Milk intake of breast fed infants. J Pediatr Gastroenterol Nutr. 1987;6(5):758-63. https://doi.org/10.1 097/00005176-198709000-000171987.

22. IAEA. Stable Isotope Technique to Assess Intake of Human Milk in Breastfed Infants. IAEA Hum. Heal. Ser. no 7, no. 7, p. 81, 2010, [Online]. Available: http://www.iaea.org/books.

23. Kent JC, Perrella SL, Geddes DT. Measurement of human milk production and infant milk intake-challenges and opportunities: Academic P; 2020

24. Christian P, Smith ER, Lee SE, Vargas AJ, Bremer AA, Raiten DJ. The need to study human milk as a biological system. Am J Clin Nutr. 2021;113(5):106372. https://doi.org/10.1093/ajcn/nqab075.

25. Hennart P. Allaitement maternel en situation nutritionnelle critique: adaptations et limites: Université Libre de Bruxelles; 1983.

26. Bravi F, Wiens F, Decarli A, Dal Pont A, Agostoni C, Ferraroni M. Impact of maternal nutrition on breast-milk composition: a systematic review. Am J Clin Nutr. 2016;104(3):646-62. https://doi.org/10.3945/ajcn.115.120881.

27. Casavale KO, et al. Report of a Meeting NIH workshop on human milk composition : summary and visions. 2020;6:769-79.

28. Wells JCK. Using body composition assessment to evaluate the double burden of malnutrition. Ann Nutr Metab. 2019;75(2):103-8. https://doi.org/1 $0.1159 / 000503666$

29. TJ. Roseboom, van der Meulen JH.P., Ravelli AC.J., Osmond, CD. Barker J.P., and Bleker OP., "Effects of prenatal exposure to the Dutch famine on adult disease in later life: an overview," Mol Cell Endocrinol., vol. 185, pp. 93-98, 2001, doi: https://doi.org/10.1016/0273-1177(91)90449-T.

30. Stanner SA, Bulmer K, Andres C, Lantseva OE, Borodina V, Poteen W, et al. Does malnutrition in utero determine diabetes and coronary heart disease in adulthood? Results from the Leningrad siege study, a cross sectional study. BMJ. 1997;315(7119):1342-8. https://doi.org/10.1136/bmj.315.7119.1342. 
31. Democratic Republic of Congo. Ministry of Health. Division Provinciale de santé du Sud-Kivu. Rapport d'activités de la zone de santé de Miti-Murhesa: Bukavu; 2018.

32. Programme National de Nutrition. Rapport d'enquête nutritionnelle dans les territoires du Sud Kivu, Kwango et Sankuru: Kinshasa; 2019.

33. INS. Enquête par grappes à indicateurs multiples, 2017-2018, Résumés statistiques : résultats clés de l'enquête: Kinshasa, République Démocratique du Congo; 2019.

34. Bahwere P. Contribution à l'amélioration et à l'évaluation de la prise en charge globale de l'enfant hospitalisé en Afrique Centrale (Sud-Kivu): Université Libre de Bruxelles; 2002.

35. Dramaix $M$, Hennart $P$, Brasseur D, Bahwere $P$, Mudjene $O$, Tonglet $R$, et al. Serum albumin concentration, arm circumference, and oedema and subsequent risk of dying in children in Central Africa. Br Med J. 1993; 307(6906):710-3. https://doi.org/10.1136/bmj.307.6906.710.

36. WHO. WHO child growth standards : length/height-for-age, weight-for-age, weight-for-length, weight-for-height and body mass index-for-age : methods and development: Geneva; 2006. https://doi.org/10.1111/j.14698749.2009.03503.x

37. Owino VO, Bahwere P, Bisimwa G, Mwangi CM, Collins S. Breast-milk intake of 9-10-mo-old rural infants given a ready-to-use complementary food in south Kivu, democratic republic of Congo. Am J Clin Nutr. 2011;93(6):13004. https://doi.org/10.3945/ajcn.110.006544.

38. Haisma H, Coward WA, Albernaz E, Visser GH, Wells JCK, Wright A, et al. Breast milk and energy intake in exclusively, predominantly, and partially breast-fed infants. Eur J Clin Nutr. 2003;57(12):1633-42. https://doi.org/10.1 038/sj.ejcn.1601735.

39. Owino VO, Kasonka LM, Sinkala MM, Wells JK, Eaton S, Darch T, et al. Fortified complementary foods with or without a-amylase treatment increase hemoglobin but do not reduce breast milk intake of 9-mo-old Zambian infants. Am J Clin Nutr. 2007:86(4):1094-103. https://doi.org/10.1 093/ajcn/86.4.1094

40. Dean A, Sullivan K, Soe M. OpenEpi: Open Source Epidemiologic Statistics for Public Health, Version 3.01. 2013. https://www.OpenEpi.com.

41. T. J. Lohman, A. F. Roache, and R. Martorell, "Anthropometric Standardization Reference Manual," Med Sci Sport Exerc., . 24, 8, 952, 1992 doi: https://doi.org/10.1249/00005768-199208000-00020.

42. IAEA. Introduction to Body Composition Assessment Using the Deuterium Dilution Technique with Analysis of Saliva Samples by Fourier Transform Infrared Spectrometry. IAEA Hum. Heal. Ser. no. 12, no. 12, p. 84, 2011, [Online]. Available: http://www-pub.iaea.org/books/iaeabooks/8370/ Introduction-to-Body-Composition-Assessment-Using-the-DeuteriumDilution-Technique-with-Analysis-of-Urine-Samples-by-Isotope-Ratio-MassSpectrometry.

43. Rein A, Higgins F, Preston. Application of the Agilent 4500 Series FTIR to the Stable Isotope Technique for Assessing Intake of Human Milk in Breastfed Infants. Agil Technol. 2014;5991-5140E.

44. Coward WA, Cole TJ, Sawyer MB, Prentice AM. Breast-milk intake measurement in mixed-fed infants by administration of deuterium oxide to their mothers. Hum Nutr Clin Nutr. 1982.

45. Wang ZM, Deurenberg P, Wang W, Pietrobelli A, Baumgartner RN, Heymsfield SB. Hydration of fat-free body mass: review and critique of a classic body- composition constant. Am J Clin Nutr. 1999;69(5):833-41. https://doi.org/10.1093/ajcn/69.5.833.

46. Donnen $P$, Brasseur D, Dramaix $M$, Assimbo V, Hennart P. Effects of cow's milk supplementation on milk output of protein deficient lactating mothers and on their infants' energy and protein status. Trop Med Int Heal. 1997; 2(1):38-46. https://doi.org/10.1046/j.1365-3156.1997.d01-121.x.

47. Matsiko E, Hulshof PJM, Van Der Velde L, Kenkhuis MF, Tuyisenge L, MelseBoonstra A. Comparing saliva and urine samples for measuring breast milk intake with the $2 \mathrm{H}$ oxide dose-to-mother technique among children 2-4 months old. $\mathrm{Br}$ J Nutr. 2020;123(2):232-40. https://doi.org/10.1017/S0007114519002642.

48. Kumwenda C, Dewey KG, Hemsworth J, Ashorn P, Maleta K, Haskell MJ. Lipid-based nutrient supplements do not decrease breast milk intake of Malawian infants. Am J Clin Nutr. 2014;99(3):617-23. https://doi.org/10.394 5/ajen.113.076588.

49. Mulol H, Coutsoudis A. Breastmilk output in a disadvantaged community with high HIV prevalence as determined by the deuterium oxide dose-tomother technique. Breastfeed Med. 2016;11(2):64-9. https://doi.org/10.1089/ bfm.2015.0139.
50. Da Costa THM, Haisma H, Wells JCK, Mander AP, Whitehead RG, Bluck LJC. How much human milk do infants consume? Data from 12 countries using a standardized stable isotope methodology. J Nutr. 2010;140(12):2227-32. https://doi.org/10.3945/jn.110.123489.

51. Diana A, Haszard JJ, Houghton LA, Gibson RS. Breastmilk intake among exclusively breastfed Indonesian infants is negatively associated with maternal fat mass. Eur J Clin Nutr. 2019;73(8):1206-8. https://doi.org/10.103 8/s41430-019-0458-1.

52. Butte NF, Ellis KJ, Wong WW, Hopkinson JM, O'Brian Smith E. Composition of gestational weight gain impacts maternal fat retention and infant birth weight. Am J Obstet Gynecol. 2003;189(5):1423-32. https://doi.org/10.1067/ S0002-9378(03)00596-9.

53. Taggart NR, Holliday RM, Billewicz WZ, Hytten FE, Thomson AM. Changes in skinfolds during pregnancy. Br J Nutr. 1967;21(2):439-51. https://doi.org/10.1 079/bjn19670045.

54. Sidebottom AC, Brown JE, Jacobs DR. Pregnancy-related changes in body fat. Eur J Obstet Gynecol Reprod Biol. 2001;94(2):216-23. https://doi.org/10.1 016/S0301-2115(00)00329-8.

55. Ehrenberg HM, Huston-Presley L, Catalano PM. The influence of obesity and gestational diabetes mellitus on accretion and the distribution of adipose tissue in pregnancy. Am J Obstet Gynecol. 2003;189(4):944-8. https://doi. org/10.1067/S0002-9378(03)00761-0.

56. Samuel TM, Binia A, de Castro CA, Thakkar SK, Billeaud C, Agosti M, et al. Impact of maternal characteristics on human milk oligosaccharide composition over the first 4 months of lactation in a cohort of healthy European mothers. Sci Rep. 2019;9(11767):1-10. https://doi.org/10.1038/s41 598-019-48337-4.

57. Nazlee N, Bilal R, Latif Z, Bluck L. Maternal body composition and its relationship to infant breast Milk intake in rural Pakistan. Food Nutr Sci. 2011;02(09):932-7. https://doi.org/10.4236/fns.2011.29127.

58. Leroy JL, Frongillo EA. Perspective: what does stunting really mean? A critical review of the evidence. Adv Nutr. 2019;10(2):196-204. https://doi. org/10.1093/advances/nmy101.

\section{Publisher's Note}

Springer Nature remains neutral with regard to jurisdictional claims in published maps and institutional affiliations.
Ready to submit your research? Choose BMC and benefit from:

- fast, convenient online submission

- thorough peer review by experienced researchers in your field

- rapid publication on acceptance

- support for research data, including large and complex data types

- gold Open Access which fosters wider collaboration and increased citations

- maximum visibility for your research: over $100 \mathrm{M}$ website views per year

At BMC, research is always in progress.

Learn more biomedcentral.com/submission 